\title{
A FRAMEWORK FOR DELIVERING PERSONALIZED E-GOVERNMENT TOURISM SERVICES
}

\author{
Malak Al-hassan, Helen Lu and Jie Lu \\ Quantum Computation and Intelligent Systems Centre, Faculty of Engineering and Information Technology \\ University of Technology, Sydney, P.O. Box 123 Broadway, NSW, Australia \\ $\{$ malak, helenlu, jielu\}@it.uts.edu.au
}

Keywords: e-Government, Personalization, Online tourism services, Ontology, Recommendation systems, Framework.

\begin{abstract}
E-government (e-Gov) has become one of the most important parts of government strategies. Significant efforts have been devoted to e-Gov tourism services in many countries because tourism is one of the major profitable industries. However, the current e-Gov tourism services are limited to simple online presentation of tourism information. Intelligent e-Gov tourism services, such as the personalized e-Gov (Pe-Gov) tourism services, are highly desirable for helping users decide "where to go, and what to do/see" amongst massive number of destinations and enormous attractiveness and activities. This paper proposes a framework of PeGov tourism services using recommender system techniques and semantic ontology. This framework has the potential to enable tourism information seekers to locate the most interesting destinations with the most suitable activities with the least search efforts. Its workflow and some outstanding features are depicted with an example.
\end{abstract}

\section{INTRODUCTION}

E-government uses innovative systems made possible by information and communication technology to achieve better services to citizens or businesses, as well as to enhance process and management of public sector. In the last few years, e-Gov initiatives have been launched by most of the governments around the globe (Millard et al., 2004). E-Gov initiatives cover three main activities, e-services, e-democracy, and eadministration. This study focuses on e-government services, particularly e-Gov tourism services.

It has been shown in the literature that intelligent personalization is a clear direction in the development of e-Gov services. The current e-Gov development, however, is mainly at the stage of the implementation of transaction services with a few exceptions, such as the development in Singapore and Canada (Pieterson et al., 2007; Wauters et al., 2007). Both of these countries have offered their citizens simple personalized services through their official portal websites (Accenture, 2004). More advanced and intelligent e-Gov systems are highly desirable. We have recently proposed a new conceptual framework of Pe-Gov services from citizen-centric approach (AlHassan et al., 2009). Using this framework, Pe-Gov services within a specific organization can be deliv- ered to citizens based on their interests, preferences, characteristics and personal needs without excessive input from users.

Within tourism domain, many governments around the world seek to promote tourism industry as non-profit services by providing information about attractions, activities and events that could be visited at specific destination, because tourism is one of the major profitable industries (International tourism receipts grew to 944 billion USD in 2008). E-Gov tourism services have the potential for delivering better governmental tourism services to citizens and overseas tourists, improving the quality of the provided services, improving the access to information ( 24 hours a day, 7 days a week). The current e-Gov tourism service is mainly about presenting tourism information online, but not personalized, e.g., everyone who uses the system will be exposed with the same set of information.

In order to make e-Gov tourism services more attractive to users, it has been realized that the e-Gov tourism services must be delivered in a user-centric manner, in which e-Gov could improve the delivery of its services to users on a personalized basis to ensure that heterogeneous users' needs and interests are met without excessive data input from users (Undheim and Blakemore, 2007). 
Based on our previous work (Al-Hassan et al., 2009); this paper proposes a specific framework for delivering personalized e-Gov tourism (Pe-Gov tourism) services from user-centric approach. This framework employs advanced recommender system (RS) techniques and semantic ontology to enable users to find the most interesting destinations with the most favourable attractions and the most suitable activities with least effort.

The rest of this paper is organized as follows: Section 2 reviews some of existing online tourism service systems. Section 3 presents the proposed framework in details and discusses its components. Section 4 illustrates how the framework works using an example. Finally, the conclusion and future work are highlighted in Section 5.

\section{ONLINE TOURISM SERVICES}

Tourism industry has undertaken significant evolution along the development of web-based technology. Numerous travel-related websites government and nongovernment agencies have been established to offer travel-related information and services. Nowadays, online presence of tourism information is one of the important services offered by e-Gov. Nearly, all the leading countries that adopted e-Gov initiatives offer online tourism services (Accenture, 2004). For example, Tourism NSW Government Service website (http://corporate.tourism.nsw.gov.au/) offers tourism services and information, which includes attractions, activities and events that could be visited at a specific destination. In addition, it provides some links to private travel and tourism agencies for other tourism and travel services.

The current commercial tourism service systems (i.e. websites) offer tourism services to users through using either search tools or content browsing. Several popular online travel websites have emerged, such as Expedia, Travelocity and ebookers. The offered services through tourism and travel websites could include destinations to visit, airlines and hotels reservation, tour operators, travel planning and many more (Rabanser and Ricci, 2005; Ricci et al., 2006).

Even though the existing travel-related websites can help users find interesting tourism information and services, it seems that these websites are relatively poor in aiding users to plan their trips, which includes the determination of where, when and how to go for a trip and what to do at a certain destination from the huge amount of information available. Users may spend significant amount of time and effort in finding what they really want. This could lead users to waste much more time or effort until they find their request (Fesenmaier, 2006). Additionally, tourists demand tourism products tailored to their actual preferences. On the other hand, they often have complex and multi-interests and their travel desires change rapidly and usually require the tourism products with shorter life cycles (Berka and Plnig, 2004). All these make the recommendation of the most appropriate tourism products to a specific tourist become a challenging tasks.

Commercial travel and tourism applications have started adopting intelligent techniques, such as RS techniques to assist users in choosing their preferred tourism services (Berka and Plnig, 2004; Fesenmaier, 2006). TripleHop's TripMatcher (used by www.skieurope.com) and VacationCoach's expert advice platform (used by travelocity.com) have been developed to offer recommendations to users by suggesting a list of destinations to visit (Rabanser and Ricci, 2005; Staab et al., 2002). Both systems use the content based recommendation techniques. Dietorecs RS (dietorecs.itc.it), on the other hand, has developed to provide users with personalized recommendations of complex tourist products including destinations, accommodations and activities. Dietorecs uses the case-based reasoning technique to generate recommendations (Ricci et al., 2006).

Most of the existed online travel and tourism recommendation systems only use single recommendation technique, and therefore, lack of intelligent and effective support to users, as described in the above examples (Ricci et al., 2006). Recently, an expert software agent, named "Traveller" was proposed to offer tourism services that able to help users (tourists) in planning their travels. A hybrid technique was used to build this agent, which includes two RS techniques, the collaborative filtering and the content-based recommendation techniques (Schiaffino and Amandi, 2009). Another intelligent personalized RS is proposed to recommend tourists attractions in a specific city. This system is built using applying ontology theory, bayesian network, analytic hierarchy process and spatial web service technology (Huang and Bian, 2009).

There are growing interests in building intelligent systems for e-tourism and travel applications, not only from commercial travel service providers' view point, but also from governments' view point. Unlike nongovernment agencies, where they attempt to promote tourism services as a business application, e-Gov focuses on promoting tourism services as non-profit services by introducing attractions, activities and events that could be visited at specific destination.

E-Gov tourism services should be delivered in a 
user-centric manner, in which e-Gov could improve the delivery of its services to users on a personalized basis to ensure that the actual users' needs and interests are met with least time and efforts. Intelligent system techniques, particularly RS, can be used for achieving personalization in e-Gov tourism services. However, the commonly used RS techniques in e-commence applications cannot be used directly for e-Gov services due to the special feature of e-Gov tourism services, such as enormous variety in tourism items, heterogeneous interests among the users, multi-interests for individual user, and dynamic nature of these interests. Therefore, new RS techniques are highly desirable for developing RS for e-Gov, particularly for online tourism services.

\section{FRAMEWORK OF Pe-Gov TOURISM SERVICES}

Aiming to serve citizens better and deliver the right information to the right citizen with less time and effort, we propose a conceptual framework of Pe-Gov tourism services based on our proposed framework in (Al-Hassan et al., 2009), as depicted in Figure 1. This framework is comprised of four main components: Customized User Interface (CUI), Knowledge Base Repository (KBR), Intelligent Recommendation Engine (IRE), and User Data Collector (UDC). These components are jointly work together to offer users recommendations that meet their interests and requirements. These recommendations include the most favourable attractions with the most suitable activities at a specific destination. The following subsections will give a general description of each component with focus on conceptual functionality rather than technical details.

\subsection{Customized User Interface}

A user needs to register with the system before he/she can login to the system to get recommendations on the tourism e-Gov services. The user interface of the system consists of two units: Registration or login unit, and the customized user interface (CUI) unit. The CUI unit is the interactive interface between the system and the active user. It contains the tourism items presented in a tree-like catalogue and "MyInterstAlboum". The CUI is generated based on the user's information, including user's demographic information, personal interests and preferences within the tourism e-Gov domain. Each registered user has a "MyInterestAlbum" in his/her own customized page.
"MyInterestAlbum" is used to facilitate users interactive with the system efficiently and friendly. It contains all selected tourism items that the user planning to visit or already visited, rating to the tourism items that have already been visited and a feedback to the selected tourism items. Each time a user enters the system, he or she will be asked to give a feedback and rating for any outstanding tourism item in the "MyInterestAlbum", which has been visited or conducted by the user but not rated yet. The new feedbacks and ratings that are provided by the user will be collected and stored in the user profile DB by the UDC component. The feedbacks would be used for further improvements of the system whereas the ratings would be used by IRE component for further processing.

\subsection{User Data Collector}

The user data collector component is responsible for collecting user related information to the tourism eGov services, including the demographic information, personal interests and preferences and the user's tourism e-Gov service usage history.

This component performs two tasks. Firstly, it collects user related data from the system through user registration, rating experienced items and feedbacks. Implicit and explicit acquisitions can be used for collecting user related data for web personalization (Eirinaki and Vazirgiannis, 2003; Markellou et al., 2005). The implicit acquisition will be used to collect data about citizens' preferences or interests implicitly. It can be collected via tracing a user's navigation sequences when he/she navigates the hierarchical tourism e-Gov service catalogue. While the explicit acquisition will be used during registration and interaction between the user and the system to capture users personal information, including users' demographic data, their interests and preferences through pre-defined forms, as well as to collect users' ratings of tourism items and feedbacks in "MyInterestAlboum". Secondly, UDC updates the user profile DB regularly by recording the captured data from the UI component into the KBR component.

\subsection{Knowledge Base Repository}

This component contains relevant knowledge of the tourism e-Gov domain. It contains tourism e-Gov ontology and the users profile database (DB).

\subsubsection{Tourism e-Gov Ontology}

Tourism ontology $(\mathrm{O})$ describes the fundamental concepts/classes (C) that compose the tourism e-Gov do- 


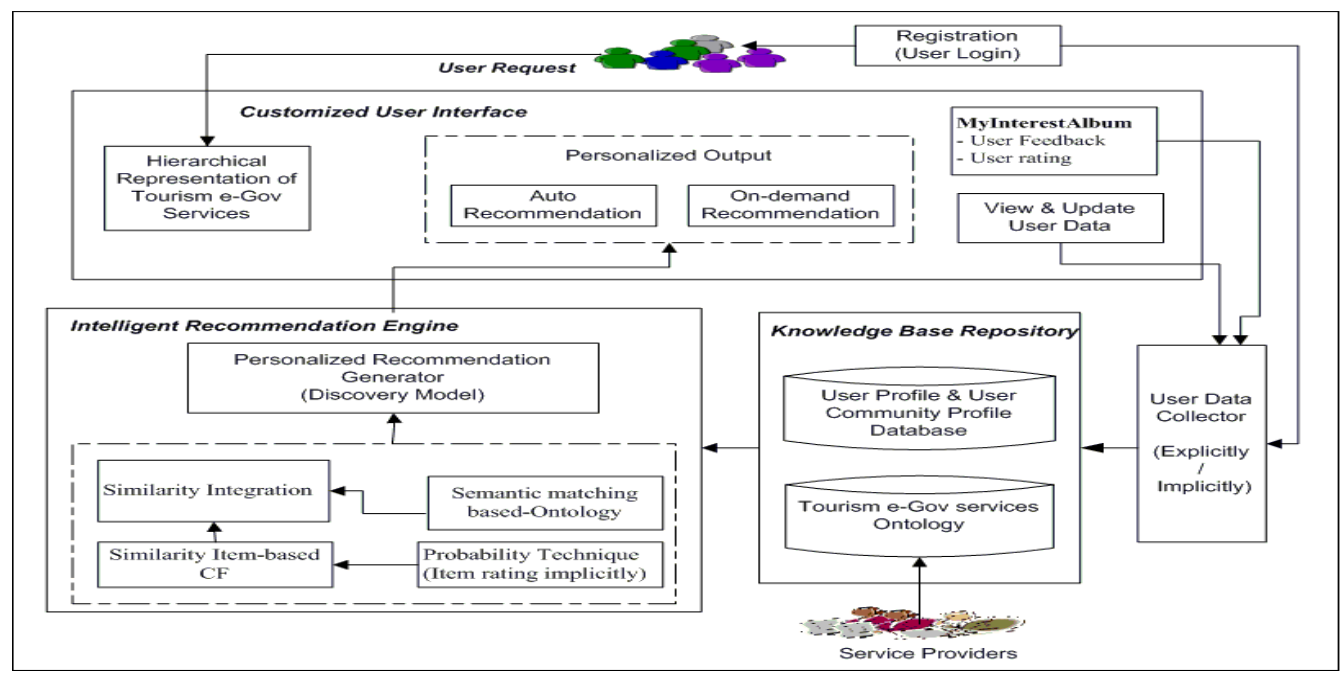

Figure 1: Framework of Pe-Gov Tourism Service System.

main; relationships among these concepts, the properties a concept can have or share. The tourism ontology under government context could include attractions, activities and events that are available at a specific destination. For this study, the Australian online information of tourism items, including attractions, activities and events, is the source to create concepts and associated relationships in the tourism e-Gov ontology. The related Australian government tourism websites have been visited to collect the required concepts to create the ontology. Typically, developing domain ontology starts with the design of the ontology schema and finishes with the populating of the ontology data (Noy and McGuinness, 2001). The ontology schema contains the definition of the various classes, properties and relationships that represent a specific domain world, whereas in the populating ontology, the instances for each class in the ontology schema can be created.

Figure 2 depicts a diagram of tourism e-Gov ontology schema. It includes the destination class, which has "attraction", "event", and "activity" subclasses. Each subclass can also have its subclasses. All classes are characterised by a set of specific properties. For example, the "Attraction" class can have properties "Time of visit" $=\{$ summer, autumn, winter, spring $\}$, "location", and "Attraction visiting purpose" $=\{$ relax, adventure, treatment, exploring $\}$. Additionally, classes are linked using relationship types. For instance, the "has-events" relationship links the "Attraction" class and the "Event" class.

Ontology schema can show the semantic relevance among tourism e-Gov concepts at different level of hierarchy (as taxonomies), therefore, it can guide the hierarchical representation of available e-
Gov tourism items in the CUI component and can be used as a means of locating and accessing services (Vassilakis and Lepouras, 2006). It can also be used by the IRE component to facilitate the semantic rule reasoning to find the matching (similarity) between the users' requests and the available tourism items, which could enhance the retrieval of the appropriate content for each user.

\subsubsection{User Profile Database}

The user profile DB contains all the data that related to users, including users' demographic data and the online tourism items that used by the users. The userrelated data is stored in the DB as two parts: static and dynamic parts. The static data part is about users' demographic data, including name, age, residential status, favourite type of attractions and general interests related to tourism. This data can be collected explicitly through the tourist account registration when a user visits the system for a first time. In contrast, dynamic data includes the preferences and interests of users that can be extracted from the interaction between users and tourism websites. In our framework, dynamic data could be the visited attractions and the activities/events that are preferred by users and their opinions (ratings) about the tourism items. This data can be attained implicitly or explicitly. Implicit data can be attained via exploring a user's web-navigation patterns (i.e. click streams) to infer the user's preferences and interests while the explicit data can be attained from "MyInterestAlbum", in which the tourism items that a user prefers and user's rating for these items are available. The user profile is a crucial part for generating recommendations. It forms one of the main sources of information that will be used to 


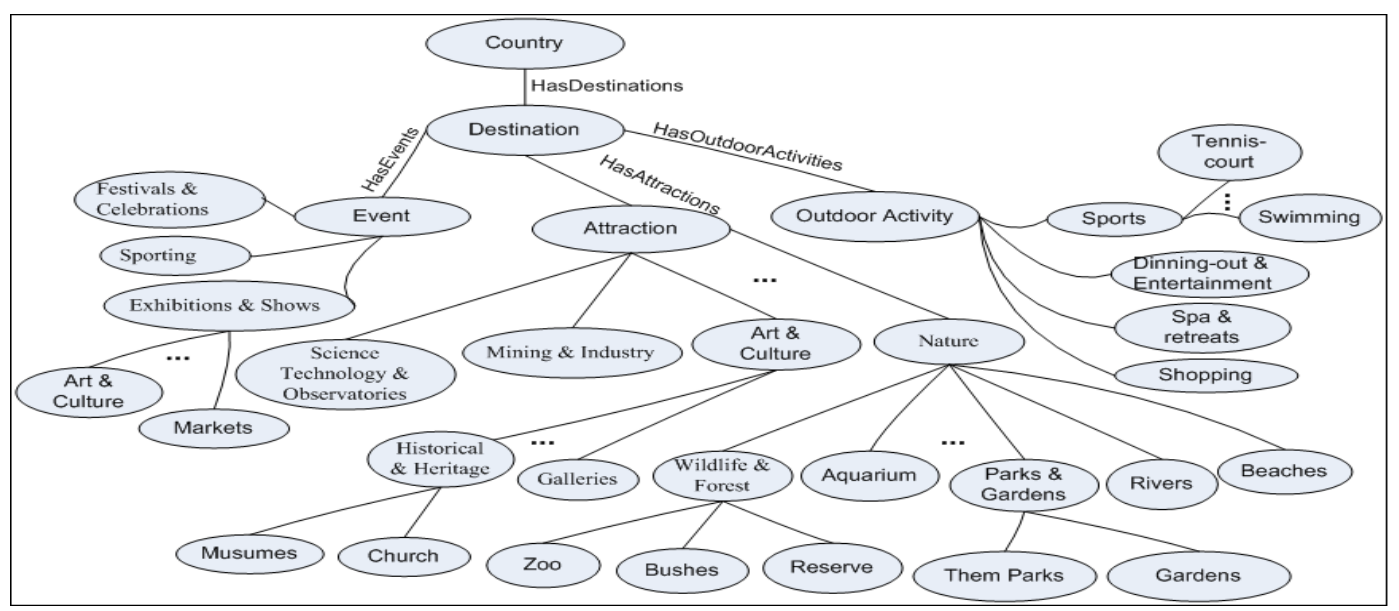

Figure 2: Tourism e-Gov Ontology Diagram.

accomplish the recommendation process in the IRE component.

\subsection{Intelligent Recommendation Engine}

This component is responsible of recommending for users the most interesting attractions and the most suitable activities at a specific destination.

IRE component uses a new hybrid methodology in order to overcome the limitations of the existing RS techniques and to enhance the recommendations. The typical RS techniques, such as the Content Based (CB) and the collaborative filtering (CF), suffer from a set of limitations which may hinder them from being directly applied to e-Gov tourism domain. For instance, the CB technique would recommend highly similar tourism items that belong to the same group or category of the given item. Hence, they ignore the items that belong to other groups but might have interest to the target user. Such technique would not be suitable for e-Gov tourism services as most of users would like to see new tourism items (Heterogeneous needs) which may be in different categories. Furthermore, the rating method used by the $\mathrm{CF}$ techniques seems not directly applicable to the e-Gov tourism domain, because it may be hard to use a single rating value to infer a person's taste as people can give the same rating to an item for vastly different reasons (Schafer et al., 2007). The CF techniques also suffers from data sparsity problem which occurs when the attained ratings are few compared to the number of the available items, and the cold-start problem which occurs when a new user or a new item enters to the system.

A combination of recommendation techniques, which called hybrid approach, is used in the literature to overcome the drawbacks of the existing techniques and to improve the recommendation performance for a particular application. Different hybrid approaches have been developed in the literature which combine $\mathrm{CF}$ with $\mathrm{CB}$ and some other techniques in different ways (Adomavicius and Tuzhilin, 2005). The new hybrid methodology, in our framework, combines the probability technique, item-based $\mathrm{CF}$, and semantic matching based-ontology to tackle the main problems in tourism services, such as the variety in the e-Gov tourism items, the multi-interest of users, and data saving and retrieving of e-Gov tourism data. This methodology consists of the following four steps:

Step 1. Develop a probability-based technique to find implicitly the rating of items.

A probability-based technique will be developed to calculate the rating of items for each user based on users' profiles. This technique consists of the following two stages:

- Cluster users into a number of groups, called communities. Each community includes a group of users who share common interests. User communities will help IRE to solve the new user problem. The system will recommend proper tourism items to a new user based on his or her user community profile.

- Apply a probability technique to compute implicitly the rating values of items for the users in each community. The rating of a specific item will be generated based on the following three criteria: (1) previous user behaviour, (2) the preferences of user's neighbours to a specific item, and (3) the semantic relevance among concepts at different level of hierarchy in the domain ontology. The third criterion is useful for inferring whether a given item is related to the concepts that are preferred by a specific user. 
In tourism domain, it is difficult to attain explicit rating for all tourism items, such as destinations, attraction and activities. This technique can find implicit ratings for unrated items for a particular user. Hence, the sparsity problem associated with the item-based CF can be alleviated.

Step 2. Find similarity among e-Gov tourism items using CF item-based similarity.

In this step, the obtained implicit ratings of items from step 1 and the explicit ratings of items that rated by users will be used to compute similarities among all instances of tourism e-Gov ontology concepts. One of the popular CF algorithms, the item-based CF algorithm will be utilized for the similarity calculations (Adomavicius and Tuzhilin, 2005). Item-based $\mathrm{CF}$ algorithm has shown better results than user-based $\mathrm{CF}$ one in terms of enhancing the performance and the quality of recommendation (Sarwar et al., 2001).

Step 3. Develop a semantic matching basedontology approach to compute similarity among the available instances of concepts (tourism items) in the tourism e-Gov ontology.

Ontology can support find the matching (or similarity) of objects that are conceptually close but not identical. A few methods have been proposed to assess similarities among instances within ontology. Ehrig and his colleagues (2005) presented a comprehensive framework for measuring semantic similarity within and between ontologies. The framework identified three main levels on which the similarity between two entities (concepts or instances) can be measured: data layer, ontology layer, and context layer, which deal with the data representation, ontology meaning, and the usage of these entities, respectively (Ehrig et al., 2005).

To find similarities among instances of tourism e-Gov ontology, semantic matching will take into account the structural comparison between two instances in terms of their classes, and the comparison between their attributes and their relations. These comparisons can be inferred using semantic analysis of the inference rules which interconnect instances in the ontology. The involved attributes and relations in comparison of different instances will be determined based on the context of the tourism e-Gov ontology.

Step 4. Generate recommendations by integrating the similarities.

The obtained similarities from steps 2 and 3 will be combined together for each tourism item and the combined similarity will be stored in KBR component as a matrix. This combined similarity will be used to build a discovery model. This model can be used to predict the most relevant item among the available tourism items that a particular user might be interested in. Weighted sum model and regression model are examples used in recommendation systems for prediction (Sarwar et al., 2001).

Combination of the ontology based semantic matching and the similarity from the item-based $\mathrm{CF}$ would improve the quality of recommendations and the prediction of new tourism items from different categories that could be preferred by a specific user. The main reason for this combination is that the generated recommendations do not merely depend on the opinions of users to the preferred items, but also on the semantic matching of these items based on their underneath hierarchal structure and their attributes and relationships that could affect the application context. Additionally, considering semantic matching in this integration could eliminate the sparsity problem if the item-based CF similarity algorithm.

\section{WORKFLOW OF Pe-Gov TOURISM SERVICE SYSTEM}

Under the proposed framework, the e-Gov tourism service systems allow users to get specific information about "where to go" or "what to do/see" at a specific destination. Figure 3 illustrates a workflow example of the system.

Example of a scenario: Jack is a local user in Australia; he wants to visit a Museum (as an attraction) at a specific destination (e.g. Sydney). How the proposed framework can help?

Jack is a registered member in the system, so he needs to login to the system using his own user name and password, as depicted in Figure 3. After login to the system, he can see his own page. A catalogue of all available tourism items (destinations and its attractions and associated activities) presented in a style of directory tree as categories. He can browse the catalogue tree staring from select "Sydney" under the destination category. Then, browse tourism attractions related to Sydney until he finds the Museum attraction node, and select this node. This selection will automatically trigger the IRE component to generate the most interested museums attraction items to Jack.

The discovery model in IRE component is responsible of generating recommendations. To accomplish that, both of Jack's profile (including his rating record) and the combined similarity matrix (that obtained from the item-based CF similarity and the semantic-based similarity, as described in section 3.4, particularly, the one related to the museum category) 


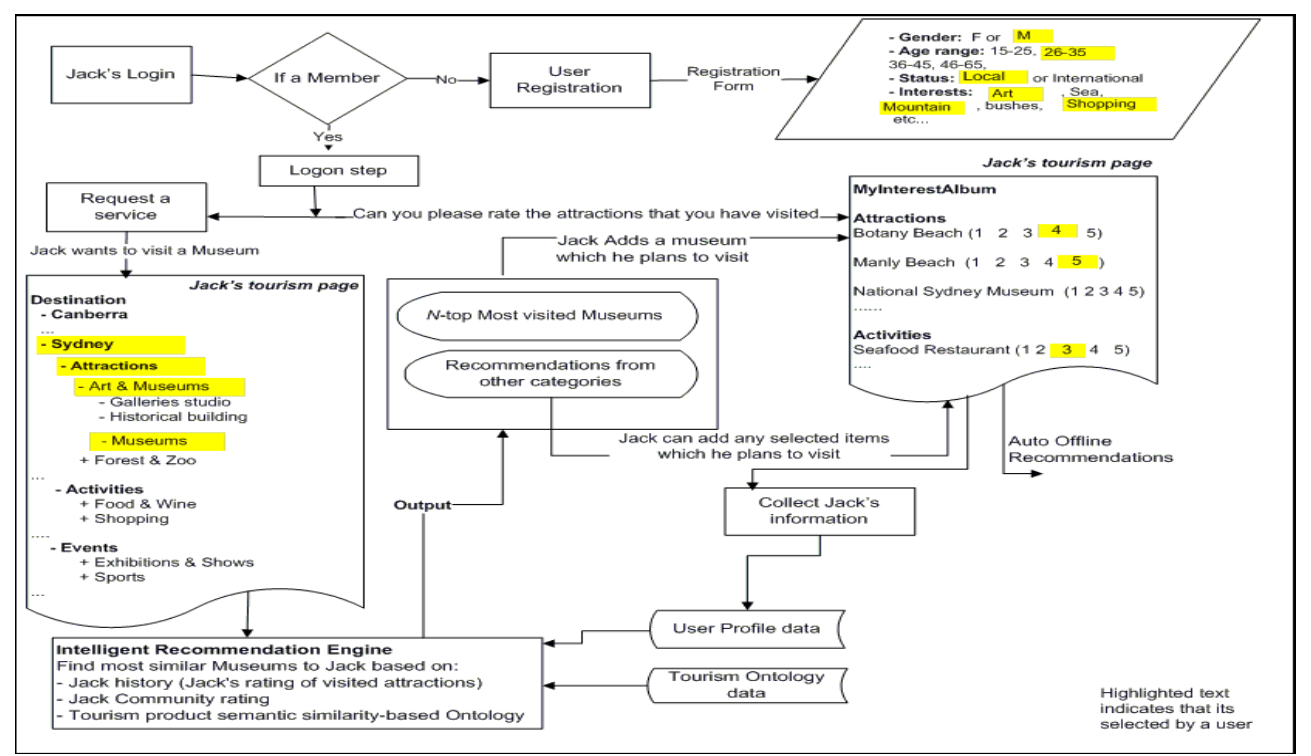

Figure 3: A Description Scenario of the workflow of Pe-Gov Tourism Service System.

will be uploaded to the memory. Then the discovery model will use, for example, a weighted sum model to predict the most interested museum items in Sydney. To perform the prediction, the weighted sum model works as follow: Firstly, it finds for each unrated museum item by Jack the most similar museums using the combined similarity matrix; Secondly, it computes for each given unrated item the intersection set between the most similar museums items to the given one and the already rated museums items by Jack; Finally, the gained intersection set will be used to compute the prediction value for this unrated item. The prediction value for each unrated museum item of Jack can be computed as a ratio of summation of the ratings given by Jack on the museums items similar to the given unrated one. Each rating will be weighted by the corresponding similarity between the given unrated item and those ones in the intersection set. Based on the computed prediction values for unrated museums items of Jack, the system will generate the top-N most interested items (higher predicted items) as an ordered list of recommendation in the GUI component.

After that Jack can browse the retrieved museum items list until he chooses a specific museum attraction item. The system, subsequently, will present for each selected museum item the most similar museums. That can be carried out according to the combined similarity matrix that explained in step 4 , in section 3.4. Beside that, the system also will ask him whether he is planning to visit this selected Museum. If the answer is positive, the system will ask Jack to add this attraction to his own "MyInterestAlbum". Generating a few most relevant museums items (top-
N) for Jack will save his significant amount of time and effort, and will bring his pleasant searching experience.

The recommendation that generated upon Jack's request is called on-demand recommendation. The on-demand recommendation could be homogenous or heterogeneous recommendation. Homogenous recommendation includes recommendations to tourism items that belong to the same category of the requested item, as in the above case, where an ordered list of Museums is generated upon Jack's request. While heterogeneous recommendation involves recommendations to tourism items from different categories that are similar to the requested item. Heterogeneous recommendation can be generated based on the given user's similar neighbours (with similar community or behaviour) and semantic similarity among tourism items. The recommendation will be presented to users in UI component as an ordered list of recommendation by category. Figure 3 depicts that Jack can receive also recommendations from other categories that are similar to the Museum, e.g., items from Galleries Studio category.

Furthermore, the intelligent Pe-Gov tourism service system can present new recommendations to users each time they login to the system. For instance, the system will recognize Jack each time he visits the system and regularly will update the content of his page automatically, a new suggestions for tourism items can be presented. These auto recommendations can be generated dynamically offline to users depending on users profile, their community and the changes that might be occurred to any tourism items. For example, new events of a specific attraction can be 
recommended for users who are interested in or visited that attraction. Interestingly, the system would be more effective for regular users who visit the system frequently. Irregular users would also be offered recommendations but limited to their available information.

\section{CONCLUSIONS AND FUTURE WORK}

Intelligent personalization has become a clear direction in the development of delivering e-Gov services by different government agencies. This paper proposes a new conceptual framework for delivering PeGov tourism services using RS techniques and semantic ontology. The proposed framework can help users find, efficiently and friendly, the most interesting tourism attractions with the most appropriate activities/events according to their interests, needs and the behaviour/experience of other similar users. The main components of this framework were discussed. The potential of the proposed framework of offering better tourism services to users has been illustrated by a scenario example. The future direction, of our research, would be to develop a working system/prototype to deliver Pe-Gov tourism services to users.

\section{REFERENCES}

Accenture (2004). egovernment leadership: high performance, maximum value. fifth annual accenture egovernment study.

Adomavicius, G. and Tuzhilin, A. (2005). Toward the next generation of recommender systems: A survey of the state-of-the-art and possible extensions. IEEE Tran. on Know. and Data Eng., 17(6):734-749.

Al-Hassan, M., Lu, H., and Lu, J. (2009). A framework for delivering personalized e-government services from a citizen-centric approach. In Proceed. of the 11th Inter. Conf. on Inf. Integration and Web-based Applications and Services.

Berka, T. and Plnig, M. (2004). Designing recommender systems for tourism. In Proceedings of ENTER.

Ehrig, M., Haase, P., Stojanovic, N., and Hefke, M. (2005). Similarity for ontologies-a comprehensive framework. In 13th European Conf. on Inf. Systems.

Eirinaki, M. and Vazirgiannis, M. (2003). Web mining for web personalization. ACM Transactions on Internet Technology (TOIT), 3(1):1-27.

Fesenmaier, D. (2006). Introduction: Recommendation systems in tourism. In Fesenmaier, D., Wober, K., and
Werthner, H., editors, Destination Recommendation Systems: Behavioral Foundations and Applications.

Huang, Y. and Bian, L. (2009). A bayesian network and analytic hierarchy process based personalized recommendations for tourist attractions over the internet. Expert Systems with Applications, 36(1):933-943.

Markellou, P., Mousourouli, I., Sirmakessis, S., and Tsakalidis, A. (2005). Personalized e-commerce recommendations. In Proceedings of the 2005 IEEE Inter. Conf. on e-Business Engineering, pages 245-252. IEEE Computer Society.

Millard, J., Havliek, J., Ticha, I., and Hron, J. (2004). Strategies for the future egovernment. In The Inter. Conf. Agrarian Perspectives XII. CAB Abstracts.

Noy, N. and McGuinness, D. (2001). Ontology development 101: A guide to creating your first ontology. Technical report, Stanford Knowledge Systems Laboratory Technical Report KSL-01-05 and Stanford Medical Informatics Technical Report.

Pieterson, W., Ebbers, W., and Dijk, J. (2007). Personalization in the public sector: An inventory of organizational and user obstacles towards personalization of e-services in the public sector. Government Information Quarterly, 24(1):148-164.

Rabanser, U. and Ricci, F. (2005). Recommender systems: Do they have a viable business model in e-tourism? In Frew, A., editor, Information and Communication Technologies in Tourism, pages 160-171. Springer.

Ricci, F., Fesenmaier, D., Mirzadeh, N., Rumetshofer, H., Schaumlechner, E., Venturini, A., Wober, K., and Zins, A. (2006). Dietorecs: A case-based travel advisory system. In Fesenmaier, D., Wober, K., and Werthner, H., editors, Destination Recommendation Systems: Behavioral Foundations and Applications.

Sarwar, B., Karypis, G., Konstan, J., and Reidl, J. (2001). Item-based collaborative filtering recommendation algorithms. In Proceed. of the 10th Inter. Conf. on $W W W$. ACM.

Schafer, J. B., Frankowski, D., Herlocker, J., and Sen, S. (2007). Collaborative filtering recommender systems. In Brusilovsky, P., Kobsa, A., and Nejdl, W., editors, The Adaptive Web, pages 291-324. Springer.

Schiaffino, S. and Amandi, A. (2009). Building an expert travel agent as a software agent. Expert Systems with Applications, 36(2):1291-1299.

Staab, S., Werthner, H., Ricci, F., Zipf, A., Gretzel, U., Fesenmaier, D., Paris, C., and Knoblock, C. (2002). Intelligent systems for tourism. IEEE Intelligent Systems, 17(6):53-64.

Undheim, T. A. and Blakemore, M. (2007). A handbook for citizen-centric egovernment.

Vassilakis, C. and Lepouras, G. (2006). An ontology for e-government public services. Encyclopedia of ECommerce, E-Government and Mobile Commerce.

Wauters, P., Nijskens, M., and Tiebout, J. (2007). The user challenge, benchmarking the supply of online public services. 

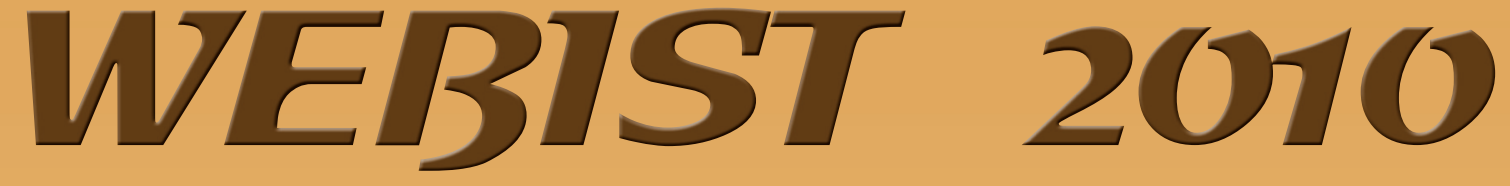

$6^{\text {th }}$ International Conference on

Web Information Systems and Technologies

\section{Proceedings}

Volume 2

Valencia, Spain · April 07 - 10, 2010 


\title{
WEBIST 2010
}

\author{
Proceedings of the \\ 6th International Conference on \\ Web Information Systems and Technology
}

Volume 2

Valencia, Spain

April 7 - 10, 2010

Organized by

INSTICC - Institute for Systems and Technologies of Information, Control and Communication

In Cooperation with

WfMC - Workflow Management Coalition

ACM SIGMIS - Association for Computing Machinery / Special Interest

Group on Management Information Systems 
Copyright (c) 2010 INSTICC - Institute for Systems and Technologies of Information, Control and Communication

All rights reserved

Edited by Joaquim Filipe and José Cordeiro

Printed in Portugal

ISBN: 978-989-674-025-2

Depósito Legal: 306973/10

http://www.webist.org/

webist.secretariat@insticc.org 


\title{
Organizing AND Steering Committees
}

\author{
Conference Chair \\ Joaquim Filipe, Polytechnic Institute of Setúbal / INSTICC, Portugal \\ Program Chair \\ José Cordeiro, Polytechnic Institute of Setúbal / INSTICC, Portugal
}

Proceedings Production

Helder Coelhas, INSTICC, Portugal

Andreia Costa, INSTICC, Portugal

Bruno Encarnação, INSTICC, Portugal

Bárbara Lima, INSTICC, Portugal

Raquel Martins, INSTICC, Portugal

Carla Mota, INSTICC, Portugal

Vitor Pedrosa, INSTICC, Portugal

Filipa Rosa, INSTICC, Portugal

José Varela, INSTICC, Portugal

\section{CD-ROM PRODUCTION}

Elton Mendes, INSTICC, Portugal

Pedro Varela, INSTICC, Portugal

Graphics Production and Webdesigner

Daniel Pereira, INSTICC, Portugal

SECRETARIAT

Bruno Encarnação, INSTICC, Portugal

WEBMASTER

Sérgio Brissos, INSTICC, Portugal 


\section{AuXiliary ReViewers}

Mutaz Al-Debei, Brunel University - West London, U.K.

Mohammad AL Asswad, Brunel Unisersity, U.K.

Paul Beskow, Simula Research Laboratory, Norway

Duygu Celik, EMU, Turkey

Alberto Corni, University of Modena e Reggio Emilia, Italy

Stuart Cunningham, Glyndwr University, U.K.

Elton Domnori, Universita' di Modena e Reggio Emilia, Italy

Adrián Fernández, Universidad Politécnica de Valencia, Spain
Cristina Gomez, Universitat Politècnica de Catalunya, Spain

Carmine Gravino, University of Salerno, Italy

Carlos Guerrero, Universitat De Les Illes Balears, Spain

Nigel Houlden, Glyndwr University, U.K.

Mehdi Khouja, Universitat de les Illes Balears, Spain

Isaac Lera, Universitat de les Illes Balears, Spain

Federica Sarro, Università degli Studi di Salerno, Italy

Eduardo Gonçalves da Silva, University of Twente, The Netherlands

\section{Selected Papers Book}

A number of selected papers presented at WEBIST 2010 will be published by Springer-Verlag in a LNBIP Series book. This selection will be done by the Conference Chair and Program Chair, among the papers actually presented at the conference, based on a rigorous review by the WEBIST 2010 Program Committee members. 


\section{FOREWORD}

This volume contains the proceedings of the Sixth International Conference on Web Information Systems and Technologies (WEBIST 2010), organized by INSTICC - Institute for Systems and Technologies of Information, Control and Communication, in collaboration with the Workflow Management Coalition (WfMC) and ACM SIGMIS.

The purpose of this Conference is to bring together researchers, engineers and practitioners interested in the technological advances and business applications of web-based information systems. It has four main topic areas, covering different aspects of Web Information Systems, including "Internet Technology", "Web Interfaces and Applications", "Society, e-Business, e-Government" and "Web Intelligence". As in last year, WEBIST is held back-to-back with CSEDU, the conference on Computer Supported Education.

WEBIST 2010 received 205 paper submissions from 46 countries in all continents. A doubleblind review process was enforced, with the help of 165 experts from the international program committee, all of them with a Ph.D. in one of the main conference topic areas. After reviewing, only 25 papers were selected to be published and presented as full papers, i.e. completed work ( 8 pages in proceedings / 30' oral presentations) and 50 additional papers, describing work-in-progress as short papers for 20' oral presentation. Furthermore 43 additional papers also will be presented as posters. The full-paper acceptance ratio was $12 \%$, and the total oral paper acceptance ratio was $36 \%$. These ratios denote a high level of quality, which we intend to maintain or reinforce in the next edition of this conference.

Besides the proceedings edited by INSTICC, a post-conference book will be compiled with extended versions of its best papers, and published by Springer-Verlag. Appropriate indexing has been arranged for the proceedings of WEBIST 2010 including DBLP, INSPEC, EI (expected) and Thomson Reuters Conference Proceedings Citation Index.

Building an interesting and successful program for the conference required the dedicated effort of many people. Firstly, we must thank the authors, whose research and development efforts are recorded here. Secondly, we thank the members of the program committee and additional reviewers for their diligence and expert reviewing. We also wish to include here a word of appreciation for the excellent organization provided by the conference secretariat, from INSTICC, who have smoothly and efficiently prepared the most appropriate environment for a productive meeting and scientific networking. Last but not least, we thank the invited speaker for his invaluable contribution and for taking the time to synthesize and deliver his talk.

Looking forward to an inspiring world-class conference and a pleasant stay in Valencia for all delegates, we hope to meet you again next year for the 7th WEBIST, details of which will be shortly made available at http://www.webist.org.

\section{Joaquim Filipe}

Polytechnic Institute of Setúbal / INSTICC, Portugal

\section{José Cordeiro}

Polytechnic Institute of Setúbal / INSTICC, Portugal 


\section{CONTENTS}

\section{INVITED SPEAKER}

\section{KEYNOTE SPEAKER}

COMMUNICATION REVOLUTIONS CHANGE CIVILIZATIONS - What to Expect from the Current One?

Žiga Turk

\section{WEB INTERFACES AND APPLICATIONS}

\section{Full Papers}

ANNOTATIONS AND HYPERTRAILS WITH SPREADCRUMBS - An Easy Way to Annotate, Refind and Share

Ricardo Kawase, Eelco Herder and Wolfgang Nejdl

SEMANTIC DRIFT IN ONTOLOGIES

Jon Atle Gulla, Geir Solskinnsbakk, Per Myrseth, Veronika Haderlein and Olga Cerrato

THE ART OF MULTI-FACETED TAGGING - Interweaving Spatial Annotations, Categories, Meaningful URIs and Tags

Fabian Abel, Ricardo Kawase, Daniel Krause, Patrick Siehndel and Nicole Ullmann

A PERSONALIZED INFORMATION SEARCH ASSISTANT

M. Elena Renda

PRAGMATICS OF STORYBOARDING - Web Information Systems Portfolios

Klaus-Dieter Schewe and Bernhard Thalheim

EFFICIENT LITERATURE RESEARCH BASED ON SEMANTIC TAGNETS - Implemented and Evaluated for a German Text-corpus

Uta Christoph, Daniel Götten and Karl-Heinz Krempels

\section{ShORT PAPERS}

A NEW ALGORITHM FOR SELF-ADAPTING WEB INTERFACES

Bogdan Vintila, Dragos Palaghita and Maria Dascalu

REVERSE MARKET SEGMENTATION WITH PERSONAS

Harri Ketamo, Kristian Kiili and Jarkko Alajääski

A REFERENCE ONTOLOGY BASED APPROACH FOR SERVICE ORIENTED ONTOLOGY MANAGEMENT

Shuying Wang, Jinghui Lu and Miriam A. M. Capretz

INTEGRATION OF SPATIAL TECHNOLOGIES AND SEMANTIC WEB TECHNOLOGIES FOR INDUSTRIAL ARCHAEOLOGY

Ashish Karmacharya, Christophe Cruz, Frank Boochs and Franck Marzani

DEVELOPING A WEB-BASED MIS SYSTEM FOR OCCUPATIONAL HEALTH

Thomas Connolly, April MacPhail and David G. W. Scott 
TOWARDS A QUALITY EVALUATION FRAMEWORK FOR MODEL-DRIVEN WEB ENGINEERING METHODOLOGIES

F. J. Domínguez-Mayo, M. Mejías, M. J. Escalona and A. H. Torres

gvSIGDROID - An Open Source Gis Solution for the Android Platform

Cristian Martín-Reinhold, Joaquín Huerta and Carlos Granell

SensorGIS - An Integrated Architecture for Information Systems based on Sensor Networks

Jianzhao Huang, Nicholas M. Boers, Eleni Stroulia, Pawel Gburzynski and Ioanis Nikolaidis

A COMPARATIVE STUDY OF THESAURI TOOLS - A Perspective from Integrability in Information Systems

Beatriz Perez-León and M. Mercedes Martínez-González

EMOTION-BASED MUSIC RETRIEVAL USING CONSISTENCY PRINCIPLE AND MULTI-QUERY METHOD

Song-Yi Shin, Joonwhoan Lee, Kyoung-bae Eum and Eun-Jong Park

eHUMANITIES DESKTOP - An Architecture for Flexible Annotation in Iconographic Research Rüdiger Gleim, Paul Warner and Alexander Mehler

TOOL DEVELOPMENT TO SUPPORT LEARNING, IMMEDIATE FEEDBACK, AND CONTINUOUS ASSESSMENT IN LOGIC

Antonia Huertas and Enric Mor

A NEW SUPPORT FOR OBJECTS CLASSIFICATION IN MULTIMEDIA INFORMATION RETRIEVAL

Walter Balzano, Maria Rosaria Del Sorbo and Antonio Tarantino

PDF/A - TOWARDS A TRUE DIGITAL ARCHIVAL SURROGATE (DAS) FOR DIGITAL MANUSCRIPT COLLECTIONS

Rodney Obien and Jeffrey Monseau

A HUB ARCHITECTURE FOR SERVICE ECOSYSTEMS - Towards Business-to-Business Automation with an Ontology-enabled Collaboration Platform

Alex Norta

WEB-BASED 'COMPUTER ASSISTED SURGICAL ANATOMY MAPPING'

A. L. A. Kerver, G-J. Kleinrensink, N. N. Smit, S. Rabbelier, B. M. W. Sedee and C. P. Botha

WEB ACCESSIBILITY - Portuguese Web Accesibility with WCAG-1.0 and WCAG-2.0

Ramiro Gonçalves, José Martins, Jorge Pereira and Henrique Mamede

\section{SOCIETY, E-BUSINESS AND E-GOVERNMENT}

\section{Full Papers}

WEB SITE BRAND ATTRIBUTES AND E-SHOPPER LOYALTY - A Comparative Study of Spain and Scotland

Sandra Loureiro and Silvina Santana

A FRAMEWORK FOR DELIVERING PERSONALIZED E-GOVERNMENT TOURISM SERVICES

Malak Al-hassan, Helen Lu and Jie Lu

BUILDING A COMMUNITY INFORMATION SYSTEM FOR SUPPORTING DISABLED BUS RIDERS AND LOCAL BUSINESSES 